\title{
PRELIMINARY STUDIES ON SEDIMENT CORE FROM THE TYRO BASIN
}

\author{
Geraga M. ${ }^{1}$, Anagnostou Ch. ${ }^{2}$, Iliopoulos $\mathrm{I}^{3}$ and Kontali M. ${ }^{1}$ \\ ${ }^{1}$ Laboratory of Marine Geology and Physical Oceanography, Department of Geology, University \\ of Patras, 26504 Patras, mgeraga@upatras.gr \\ ${ }^{2}$ Institute of Oceanography - Hellenic Centre for Marine Research, 19013 Anavyssos Attikis, \\ chanag@hcmr.gr \\ ${ }^{3}$ Laboratory of Mineral and Rock Research, Department of Geology, University of Patras, 26504 \\ Patras,morel@upatras.gr
}

\begin{abstract}
The present paper summarizes the preliminary results of the mineralogical and micropaleontological analysis conducted on sediment samples from core TYR05 retrieved from the anoxic and hypersaline Tyro basin in the eastern Mediterranean Sea. The core comprises a complex lithostratigraphic sequence attributed to the strong geodynamic regime of the area. The planktonic foraminifera associations present fluctuations which coincide with changes in the lithology of the core. The mineralogical composition of the sediments shows influence from the evaporites developed on the bottom of the basin. The mineral constituents in association to the microfauna assemblages suggest that the sediments include sapropelic layers. Further analyses are needed in order to determine safely the sapropelic deposits. Keywords: X-ray diffraction, planktonic forams, brine basins, sapropels, eastern Mediterranean.

\section{Пєрí}

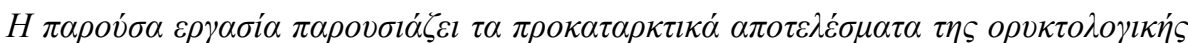

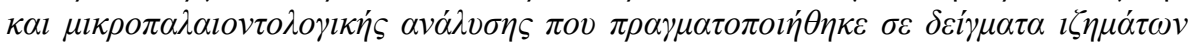

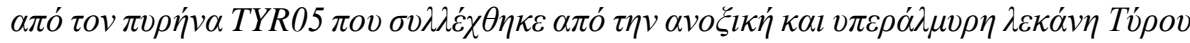

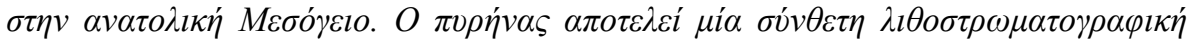

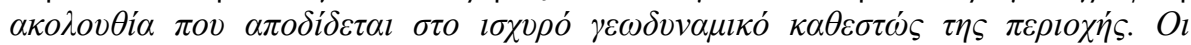

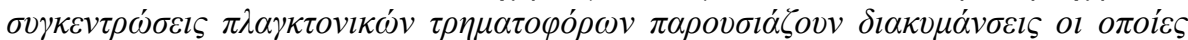

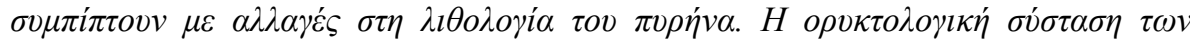

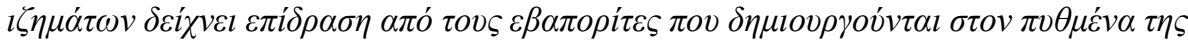

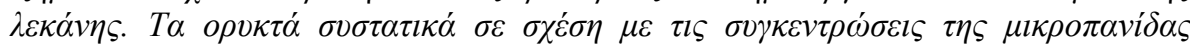

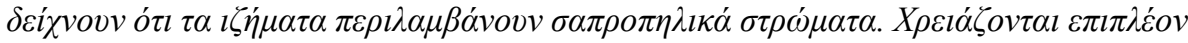

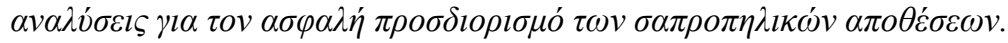

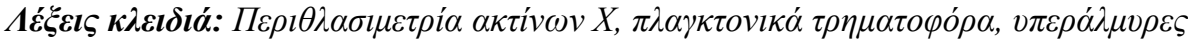

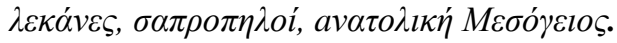

\section{Introduction}

The Tyro Basin is one of the five main hypersaline and anoxic basins (Bannock, Tyro, Urania, Atalante and Discovery) in the deep eastern Mediterranean Sea (Cita, 1991). The Tyro basin 
discovered in 1983 in the southwestern part of the Strabo Trench region (Jongsma et al., 1983). The water column above the basin is $3450 \mathrm{~m}$ and contains a layer of hypersaline water in the bottom 100 m (ten Haven et al., 1987). Drastic changes in the water parameters occur rapidly, in less than $1 \mathrm{~m}$ depth interval at the interface of the brine and the normal seawater: the salinity increases to almost 10 times the value of the normal Mediterranean water and the temperature to about $1.5^{\circ} \mathrm{C}$, in relation to the overlying seawater producing a stable physical configuration (De Lange et al., 1990). The formation of the Tyro basin, as well as of the other hypersaline basins, has been attributed to the dissolution of Messinian evaporites that outcrop the seafloor of the basins (Nesteroff, 1973; Hsü $e t$ al., 1973; Wallmann et al., 2002). In particular, the brine in Tyro basin is homogenous and its chemical compounds (relatively high $\mathrm{Na}$ content and low $\mathrm{Br} / \mathrm{C} 1$ ratio) suggest an early stage (halite) of evaporite formation (De Lange et al., 1990).

In the Tyro brine the stable water column prevents the water circulation and the dissolved oxygen drops rapidly to zero incorporating to the accumulation and the well preservation of organic rich sedimentary deposits such as the sapropels (ten Haven et al., 1987; De Lange et al., 1990). Sediment cores collected from the Tyro basin are rather rarely reported. Their sediment sequences often present disturbances by resedimentation processes due to active tectonism and are characterized by high sedimentation rates (McCoy and Stanley, 1984; Troelstra, 1987; Erba et al., 1987. Homogeneous deposition materials have been also encountered in piston cores retrieved from the same area.

In the present paper we present the preliminary results of the sedimentological analyses performed in the sediment core collected from the Tyro basin. Micropaleontological and mineralogical analyses were conducted aiming to a better understanding of the sedimentary processes taking place at the core site.

\section{Materials and Methods}

The core TYR05 was collected by R/V Aegaeo from the Tyro basin, in the framework of HCMR Research Projects. The sampling site is defined by the following coordinates: $33^{\circ} 52.245^{\prime} \mathrm{N}, 26^{\circ}$ $9.423^{\prime} \mathrm{E}$ and a water depth of $2.953 \mathrm{~m}$. The core was initially described in detail based on the variation of color and sedimentary structures.

Forty samples selected from this core for foram analysis. Each sample covered approximately a 2 $\mathrm{cm}$ thick interval in the core. The samples were treated with $\mathrm{H}_{2} \mathrm{O}_{2}$, washed and sieved over mesh widths of $63 \mu \mathrm{m}$ and $125 \mu \mathrm{m}$. The dry and weighed samples were split into separate aliquots containing about 300 planktonic foraminiferal specimens. At least 300 different planktonic specimens were identified and counted in each sample. Each taxon is expressed as a percentage of the total assemblage. The numbers of planktonic and benthic foraminifera specimens per weight of dry sediment $(>150 \mu \mathrm{m}$ and $>63 \mu \mathrm{m}$, respectively) were estimated as indexes of planktonic (PFPI) and benthic productivity (BFPI), respectively. Hierarchical cluster analysis (R-mode) was performed on the planktonic foraminifera species which were sufficiently abundant in the examined species. The tree diagram was constructed using the Ward's method based on Squared Euclidian distance on SPSS software.

A small aliquot from each sample was used in order to determine the mineralogical variation throughout the whole core length by means of X-ray powder diffraction (XRPD) analysis. Samples were firstly dried in a laboratory oven at $110^{\circ} \mathrm{C}$ for $24 \mathrm{~h}$ and then grinded in a vibration disc mill using an agate grinding set. The samples were then analysed in a Bruker D8 Advance X-Ray diffractometer, with $\mathrm{Ni}$ filtered $\mathrm{CuK} \alpha$ radiation, operating at $40 \mathrm{kV} / 40 \mathrm{~mA}$, in the Laboratory of Mineral and Rock Research of the Department of Geology at the University of Patras. The scanning area covered the interval $2^{\circ}-70^{\circ} 2 \theta$, with a scanning angle step of $0.015^{\circ} 2 \theta$ and a time step of 0.1 $\mathrm{s}$ (Iliopoulos et al., 2011). The interpretation of the acquired diffractograms and mineral identification was performed using DIFFRACplus EVA software (Bruker-AXS, Madison, WI, USA) 
based on the International Centre for Diffraction Data Powder Diffraction File (2006). All minerals identified by X-ray diffraction analysis are reported as major (>30\%), moderate (20-30\%), minor $(10-20 \%)$, few $(3-10 \%)$ and trace $(<3 \%)$ amounts.

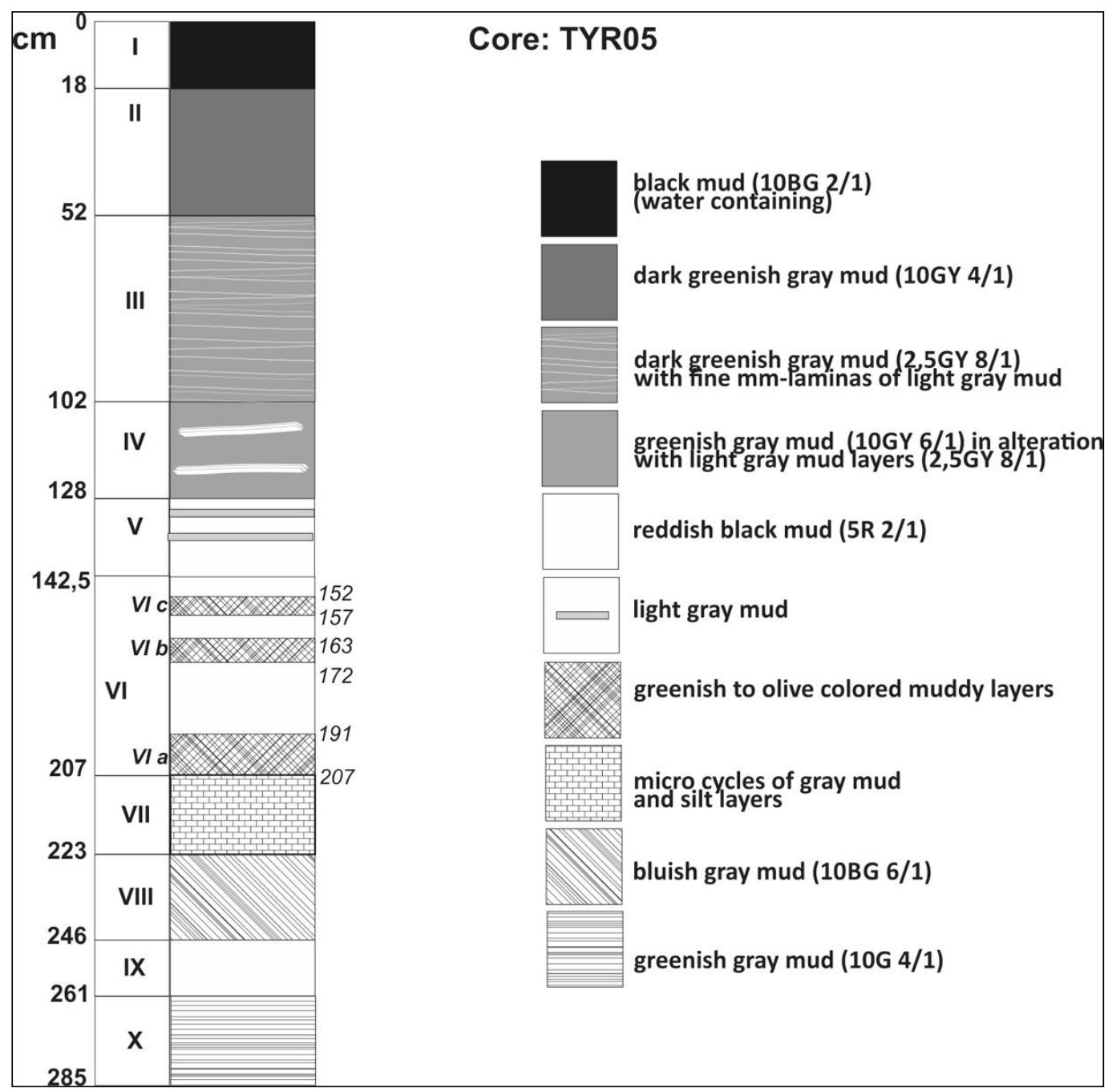

Figure 1 - Description of the core sediment.

\section{Results}

\subsection{Sediments}

The core is $285 \mathrm{~cm}$ long and consists mostly of mud. The macroscopic description showed that the core represents a rather complex sediment deposition at the core location. Ten lithological units (I$\mathrm{X}$ ) have been observed and are described in Figure 1. Noticeable are the laminas of light color which were often observed between $52 \mathrm{~cm}$ and $128 \mathrm{~cm}$, within the units III and IV. Furthermore, the unit $\mathrm{V}(128-142.5 \mathrm{~cm})$ is characterized by an alternation between light gray and reddish black mud. The same pattern continues within the unit VI $(142.5-202 \mathrm{~cm})$ but there the light gray layers are replaced by greenish to olive colored muddy layers (observed at 191-207 cm: VI a, 163.5-172 cm: VI b and 152-157 cm: VI c). 


\subsection{Mineralogical composition}

The evaluation of XRD patterns obtained from the analysis of the samples covering the entire core range helped us identify their main mineral constituents (Figs. 2 and 3). An evaporitic mineral association consisting of halite, calcite, gypsum and dolomite together with quartz dominates the mineralogical composition of all the examined samples. Among the detected evaporitic minerals $\mathrm{Mg}$-calcite and aragonite present strong variations in their content throughout the core. The former is absent between 50 and $223 \mathrm{~cm}$ and the later was detected only between 36 and $85 \mathrm{~cm}$ and 133 and $205 \mathrm{~cm}$ and always in low content. Quartz presents a lower content between 127 and $209 \mathrm{~cm}$. Clay minerals represented by illite and chlorite as well as feldspars (K-feldspar and plagioclase) are also present in almost all the examined samples. The participation of chlorite is discontinuous and presents low content between 58 and $202 \mathrm{~cm}$. Pyrite was also detected at around $50 \mathrm{~cm}$ and between 136 and $205 \mathrm{~cm}$ but in accessory quantities.

\subsection{Foraminifera}

Planktonic foraminifera are abundant in all the examined samples (Fig. 4). Their presence is lower in the core part between $20 \mathrm{~cm}$ and $30 \mathrm{~cm}$. Benthic foraminifera are also present in the same samples (Fig. 4). Their presence is reduced around the $20 \mathrm{~cm}$ core part and locally between $120 \mathrm{~cm}$ and 200 $\mathrm{cm}$ core part. Benthic foraminifera specimen are more rare in the $>125 \mu \mathrm{m}$ sediment fraction than that of the $>63 \mu \mathrm{m}$. All the examined samples contain well preserved and abundant fauna of radiolarian and pteropods.

The planktonic assemblages consist of Globigerinoides ruber alba, Gs. ruber rosea, Gs. sacculifer, Gs. trilobus, Orbulina universa, Globigerinella aequilateralis, G. calida, Hastigerina pelagica, Globoturborotalita rubescens, G. tenella Globigerina bulloides, G. falconensis, Globigerinita glutinata, Turborotalita quinqueloba, Neogloboquadrina pachyderma, N. dutertrei and Globorotalia scitula. The down core variations in the abundance of planktonic foraminifera species coincide with changes in the lithological units of the core sediments (Fig. 5).

Cluster analysis (R-mode) revealed two clusters (Fig. 6). The first cluster comprises G. glutinata, T. quinqueloba, Gr. scitula and the group of N. pachyderma and N. dutertrei together with the indexes of planktonic and benthic foraminifera productivity (PFPI and BFPI, respectively). These planktonic foram species are considered as cold water indicators (Rohling et al., 1993; Pujol and VergnaudGrazzini, 1995; Geraga et al., 2010) and their high participation in the lower part of the core (200$285 \mathrm{~cm}$ ) suggests the prevalence of cold climatic conditions during the deposition of the lithological units VII -X. This interval is also characterized by high participation of both the planktonic and benthic foraminifera fauna (Fig. 4) suggesting high levels of productivity in the surface waters and relatively high concentration in oxygen in the bottom waters.

The second cluster comprises Gs. ruber, Or. universa, the sum of Globigerinella spp. and the sum of Globoturboroatalita spp. together with G. bulloides and Gr. inflata. The former species are considered indicators of warm waters (Rohling et al., 1993; Pujol and Vergnaud-Grazzini, 1995; Geraga et al., 2010). Their high participation in the upper part of the core between the top and 200 $\mathrm{cm}$ suggests the prevalence of warm climatic conditions during the deposition of the upper lithological units (I-VII). Furthermore, G. bulloides has been related to eutrophicated waters due to river discharges (Rohling et al., 1993; Geraga et al., 2010). The increased participation of this species between $150 \mathrm{~cm}$ and $200 \mathrm{~cm}$ core interval reveals a more humid climate during the deposition of the lithological unit VI. Gr. inflata has been related to eutrophicated waters due to water mixing especially during the winter (Pujol and Vergnaud-Grazzini, 1995). The participation of this species in the above interval is low. The increase in its abundance between $130 \mathrm{~cm}$ and 150 $\mathrm{cm}$ suggests an increase of water mass circulation during the deposition of the lithological unit V. 

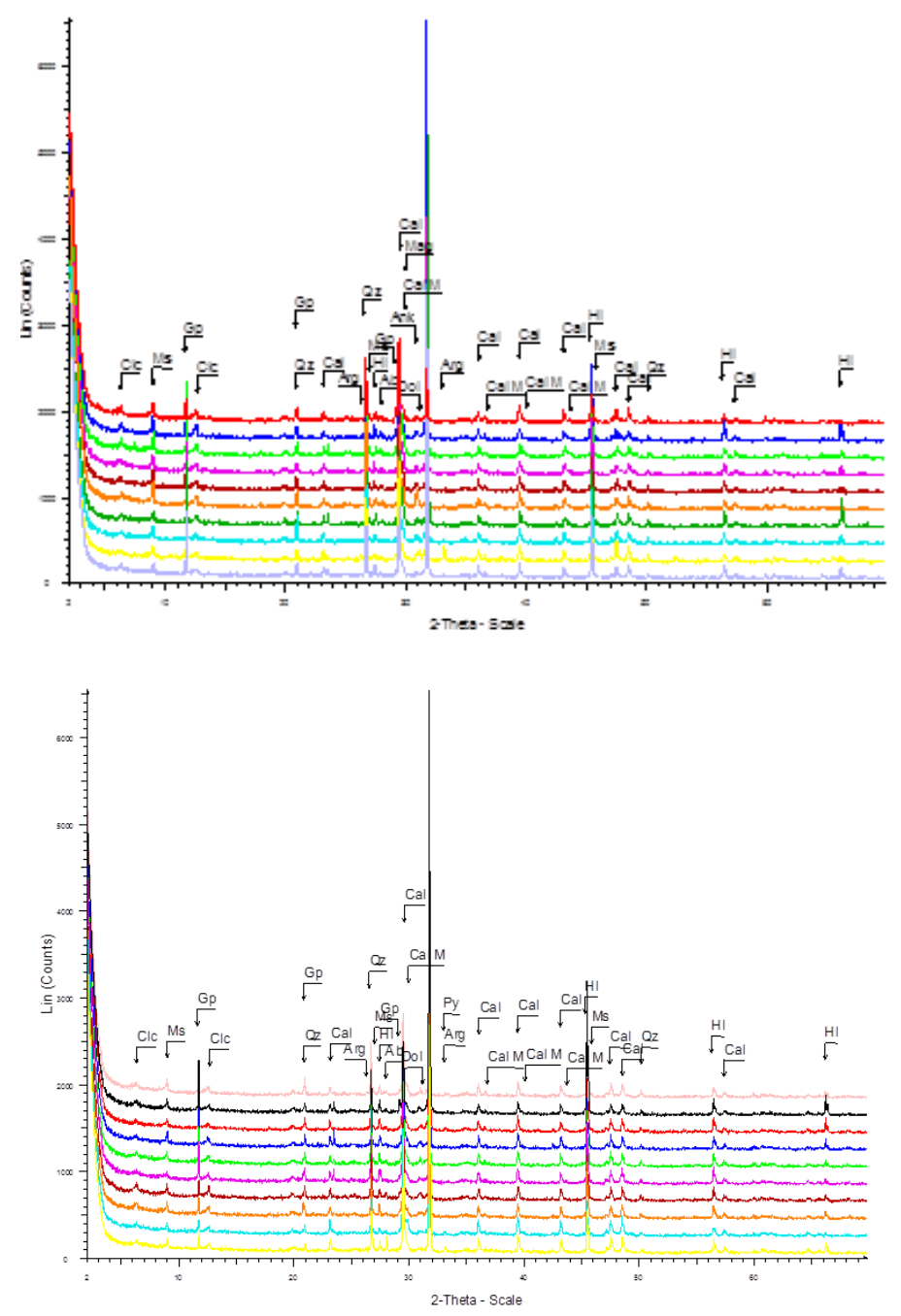

Figure 2 - Composite plots of the XRD patterns for samples obtained from 0-64 cm (up) and 70-146 cm (down). Mineral abbreviations: halite (HI); calcite (Cal); quartz (Qz); gypsum (Gp); illite (I); magnesium calcite (Mag); chlorite (Clc); dolomite (Dol); aragonite (Ar); pyrite (Py); albite (Ab).

Furthermore, juvenile assemblages are present in the majority of the samples though their presence is higher in the upper part of the core (lithological unit I). Juvenile assemblages have been obtained in sediment cores revealed from the Tyro basin and they have been related to homogeneous deposits (Troelstra, 1987). 

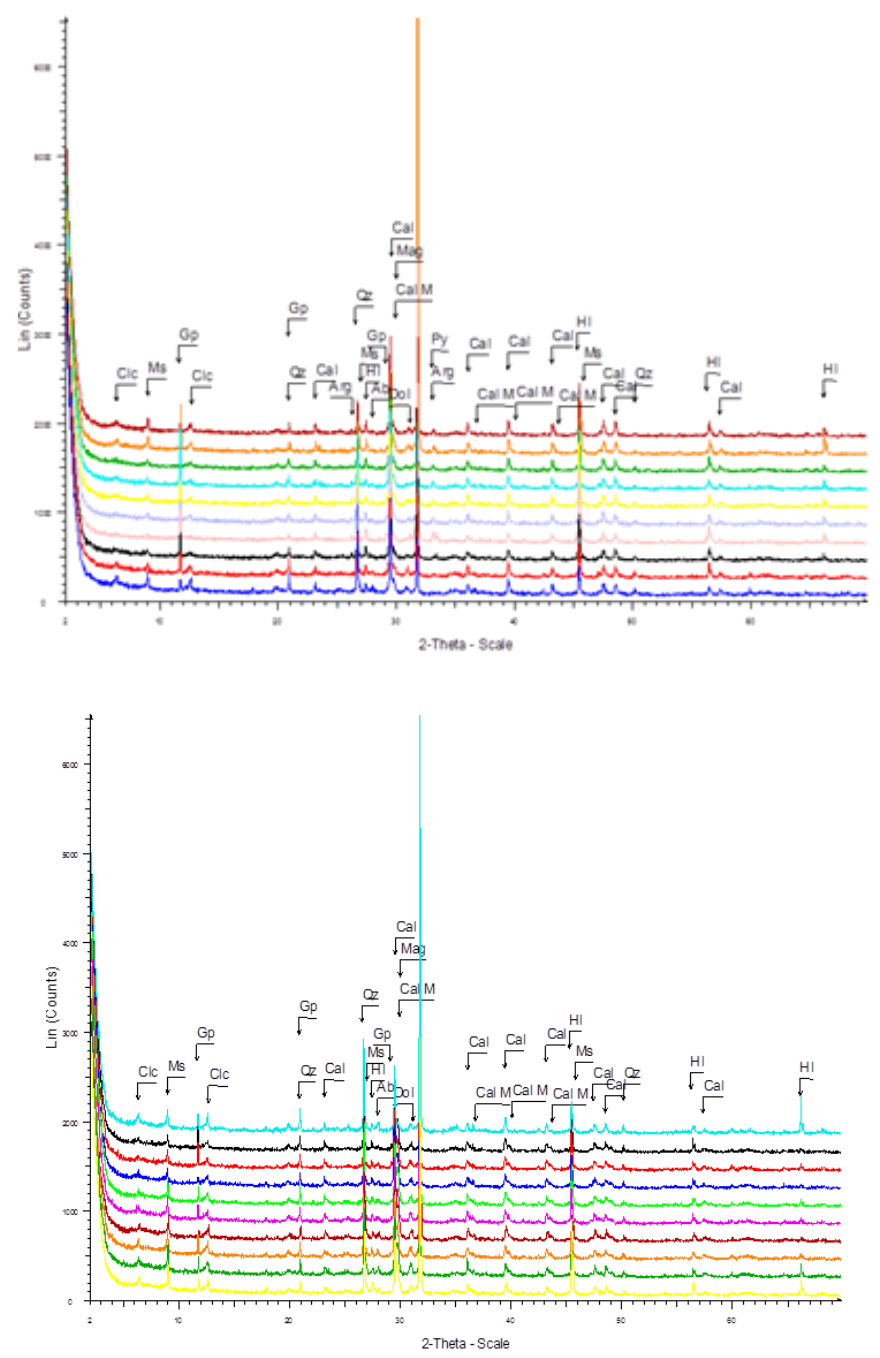

Figure 3 - Composite plots of the XRD patterns for samples obtained from 149-216 cm (up) and 219-285 cm (down). Mineral abbreviations: halite (HI); calcite (Cal); quartz (Qz); gypsum (Gp); illite (I); magnesium calcite (Mag); chlorite (Clc); dolomite (Dol); aragonite (Ar); pyrite (Py); albite (Ab).

\section{Discussion}

The mineralogical association obtained in the examined sediment samples of TYR05 core is detected frequently in the sediments of eastern Mediterranean Sea (Nesteroff, 1973). In particular, halite, calcite, gypsum, dolomite and $\mathrm{Mg}$-calcite are the dominant mineral phases in the sediments revealed from the Tyro basin (Nesteroff, 1973; ten Haven et al., 1987; De Lange et al., 1990) and other hypersaline basins (Corselli and Aghib, 1987; Wallmann et al., 2002) and appear to precipitate as the result of the dissolution of the underlying evaporates. The steady presence of these minerals in the relative records of the present study suggests the constant influence of the hypersaline environment developed in the area, at the core site. Illite and chlorite, which are present in almost all the examined samples, are among the common clay minerals observed in the sediments of the sea southern of Crete and they are considered as the alteration products of the metamorphic rocks cropping out in Crete and other islands in the same area (Ehrmann et al., 2007). 


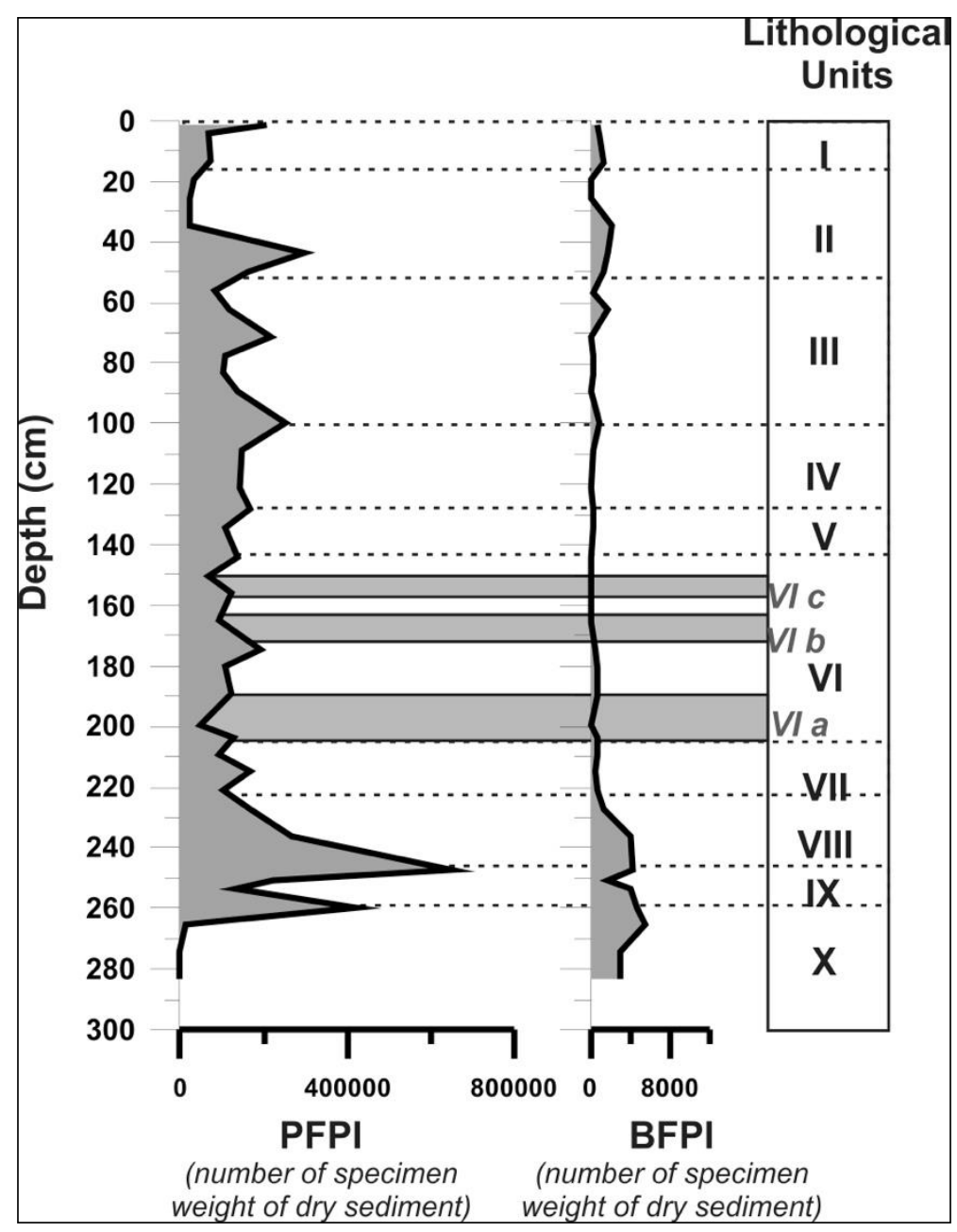

Figure 4 - Down core variations of the Planktonic and Benthic Foraminifera Productivity Indexes (PFPI and BFPR, respectively). Dashed lines indicate the boundaries of the lithological units, referred on the right.

Furthermore, illite has been related to terrigenous supply transported by rivers discharging into the Aegean Sea. The quartz content represents the coarser grained fraction in the examined samples. Previous studies in the eastern Mediterranean have shown that the proportion of quartz decreases in the sapropelic sediments as a result of low wind strength during times of sapropel formation (Calvert and Fontugne, 2001). Pyrite is also a common mineral of the sapropel deposits in the sediments of Eastern Mediterranean as a result of microbial $\mathrm{SO}_{4}$ reduction and subsequent reaction of reduced $\mathrm{S}$ with Fe, mainly during the formation of the layer (Passier et al., 1999; Calvert and Fontugne, 2001). Aragonite is also related to the sapropel formation and possible mechanisms for its presence are considered the high growth of Florisphaera profunda, the detrital origin and the sulphate reduction, during the sapropel interval (Thomson et al., 2004).

The mineralogical composition obtained from the $127 \mathrm{~cm}$ to $209 \mathrm{~cm}$ core interval, which comprises pyrite, aragonite, low quartz content and absence of Mg-calcite (Calvert and Fontugne, 2001) provides direct evidence that the lithological units V and VI include sapropelic deposits. This is further supported by the rare presence or even absence of the benthic foraminifera fauna in this interval (Fig. 4) suggesting the prevalence of anoxic bottom waters at the core site (Geraga et al., 
2010). The same pattern but of a weaker signal is obtained also from the $42 \mathrm{~cm}$ to $82 \mathrm{~cm}$ core interval within the unit III.

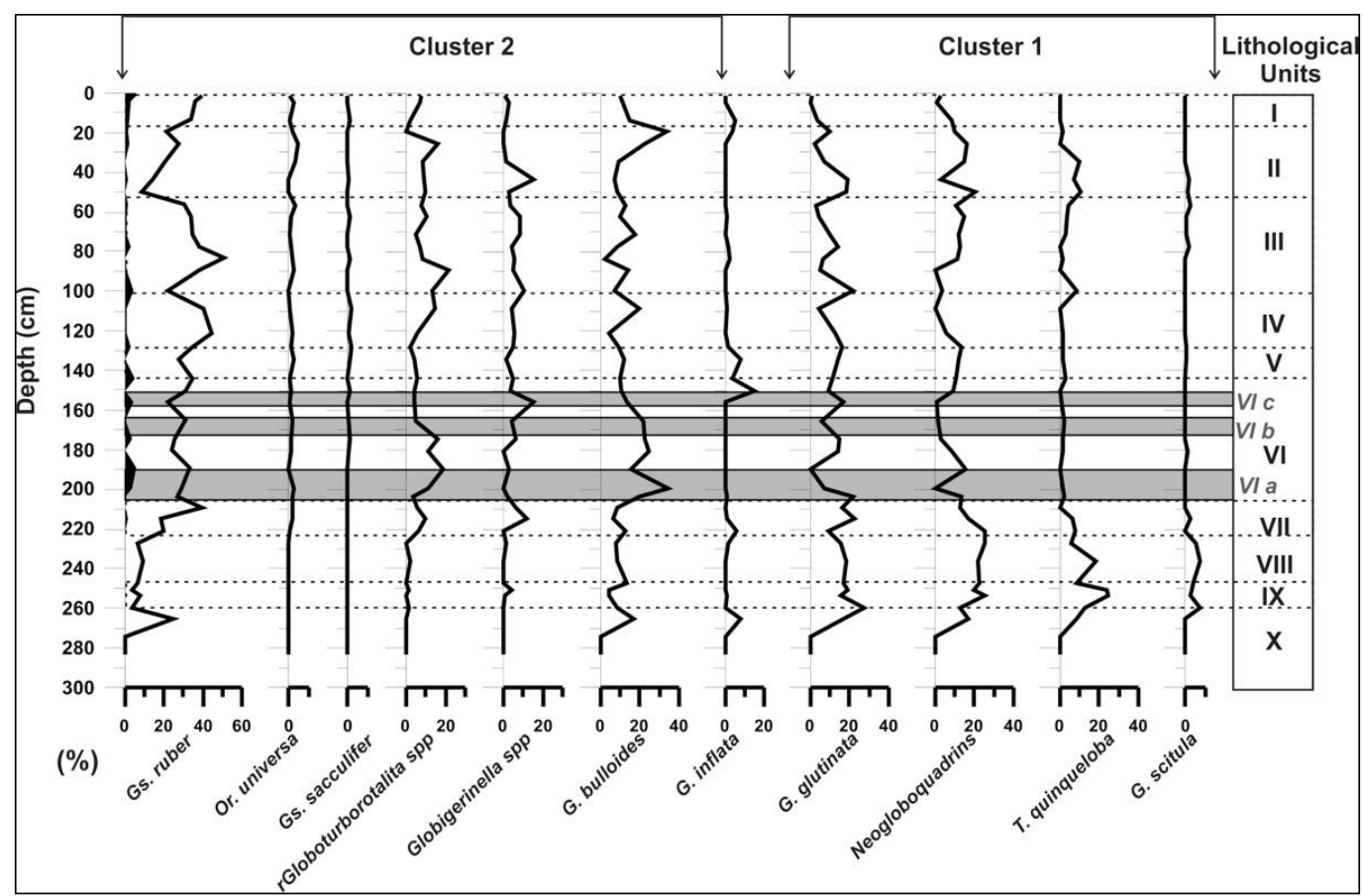

Figure 5 - Down core variation of selected planktonic species versus depth. Dashed lines indicate the boundaries of the lithological units, referred on the right. Species belonging to Clusters 1 and 2 are also shown.

According to the macroscopic observations on the stratigraphy of the core, layers VI a to VI c appear as the more likely proxy to the presence of sapropels. However, in view of the data hitherto of this study and taken into consideration the strong geo-dynamic regime of the study area (Troelstra, 1987) it was not possible to define safely if these layers correspond to deposits of different sapropels or to post depositional layers of the same sapropel. If we assume the latter case as the most possible then the comparison of the present micropaleontological study results with previous studies from sediment cores close to the Tyro basin area (Rohling et al., 1993) and nearby seas (Violanti et al., 1991; Triantaphyllou et al., 2010) points out that these layers could correspond to the S1 or S5 sapropel deposits. Both these sapropels are deposited under relative warm climatic conditions and are characterized by anoxic bottom waters as it is suggested by the absence or low participation of the benthic forams. Furthermore in these layers G. bulloides participates in the planktonic associations with percentages around $20 \%$ to $30 \%$ while the participation of the Neoqloboquadrins varies among the investigated sites from 0 to 20-30\% (Violanti et al., 1991; Rohling et al., 1993; Triantaphyllou et al., 2010). The same trends have been obtained in the studied core interval (Figs. 4 and 5). However, there is no clear evidence for the cold phase of the last glacial period, thus this study favors the scenario of the sapropel S1. 


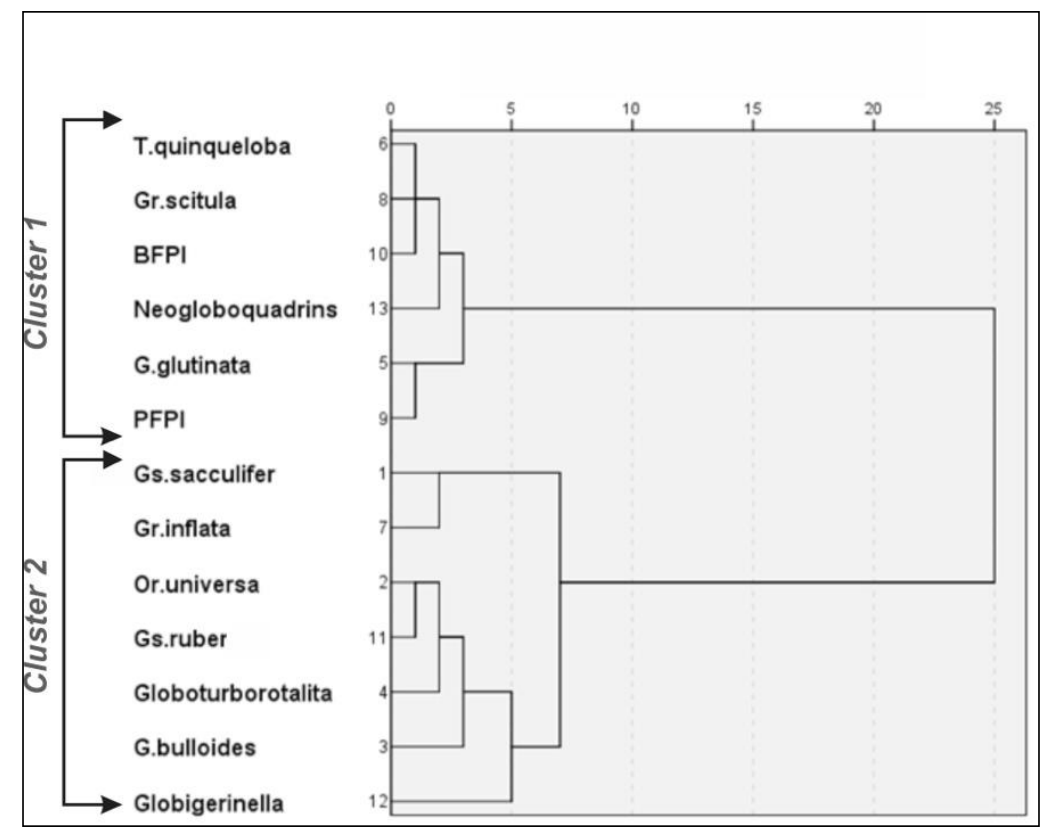

Figure 6 - R-mode cluster analysis for the dataset of the microfauna.

\section{Conclusions}

Mineralogical and micropaleontological analyses were performed on sediment samples from the core TYR 05, retrieved from Tyro basin. The preliminary results suggest that the core sediments present a complex sedimentary sequence. The microfauna assemblages present fluctuations in their abundances which coincide with changes in the lithology of the core. However, the majority of the examined samples show that the core sediments deposited under warm climatic conditions. The mineralogical composition of the sediments shows the influence of the brine which is developed in the basin. Furthermore the micropaleontological together with the mineralogical findings suggest that the core includes sapropelic layers. At this phase of the study it was not possible to determine safely these layers due to strong resedimentation processes took place in the study area.

\section{Acknowledgments}

The authors would like to thank the anonymous reviewer which helped us to improve the manuscript as well as Mrs Amalia Prandekou and Mrs Anna Grammatikou for their help in the foraminiferal analysis.

\section{References}

Calvert, S.E. and Fontugne, M.R., 2001. On the late Pleistocene-Holocene sapropel record of climatic and oceanographic variability in the eastern Mediterranean, Paleoceanography, 16, 78-94.

Cita, M.B., 1991. Anoxic basins of the eastern Mediterranean: An overview, Paleoceanography, 6(1), 133-141.

Corselli, C. and Aghib, F.S., 1987. Brine formation and gypsum precipitation in the Bannock Basin, Eastern Mediterranean, Mar. Geol., 75(1-4), 185-199.

De Lange, G.J., Middelburg, J.J., van der Weijden, C.H., Catalano, G., Luther III, G.W., Hydes, D.J., Woittiez, J.R.W. and Klinkhammer, G.P., 1990. Composition of anoxic hypersaline brines in the Tyro and Bannock Basins, eastern Mediterranean, Mar. Chem., 31, 63-88. 
Ehrmann, W., Schmiedl, G., Hamann, Y. and Kuhnt, T., 2007. Distribution of clay minerals in surface sediments of the Aegean Sea: a compilation, Int. J. Earth Sci., 96, 769-780.

Erba, E., Parisi, E. and Cita, M.B., 1987. Stratigraphy and sedimentation in the western Strabo Trench, Eastern Mediterranean, Mar. Geol., 75, 57-75.

Geraga, M., Ioakim, Chr., Lykousis, V., Tsaila-Monopolis, St. and Mylona, G., 2010. The highresolution palaeoclimatic and palaeoceanographic history of the last 24,000 years in the central Aegean Sea, Greece, Palaeogeogr. Palaeoclimatol. Palaeoecol., 287, 101-115.

Hsü, K.J., Cita, M.B. and Ryan, W.B.F., 1973. The origin of the Mediterranean evaporates. In: W.B.F. Ryan, K.J. Hsü et al., eds., Init. Reports, DSDP, 13, U.S. Government Printing Office, Washington, DC, 673-694.

Iliopoulos, I., Xanthopoulou, V. and Tsolis-Katagas, P., 2011. A petrographic assessment of houseware and storage pithoi in the Early Helladic settlement of Helike, Achaia, Greece. In: Katsonopoulou, D., ed., Helike IV, Protohelladika: Helike and Aigialeia, The Southern Greek Mainland, 127-142.

Jongsma, D., Fortuin, A.R.W., Huson, S.R., Troelstra, G.T., Klaver, G., Peters, J.M., van Harten, D., de Lange, G.J. and ten Haven, H.L., 1983. Discovery of an anoxic basin within the Strabo Trench, eastern Mediterranean, Nature, 305, 795-797.

McCoy, F.W. and Stanley, D.J., 1984. Comment, Nature, 309, 727.

Nesteroff, W.D., 1973. Petrology and mineralogy of sapropels, Init. Reports, DSDP, 13, 713-720.

Passier, H.F., Middelburg, J.J., de Lange, G.J. and Bottcher, M.E.,1999. Models of sapropel formation in the eastern Mediterranean: Some constraints based on pyrite contents, Mar. Geol., 153, 199-219.

Pujol, C. and Vergnaud Grazzini, C., 1995. Distribution patterns of live planktic forminifers as related to regional hydrology and productive systems of the Mediterranean Sea, Mar. Micropaleontol., 25, 187-217.

Rohling, E.J., Jorissen, F.J., Vergnaud-Grazzini, C. and Zachariasse, W.J., 1993. Northern Levantine and Adriatic quaternary planktic foraminifera; reconstruction of paleoenvironmental gradients, Mar. Micropaleontol., 21,191-218.

ten Haven, H.L., Bass, M., De Leeuw, J.W., Maassen, J.M. and Schenck, P.A., 1987. Organic geochemical characteristics of sediments from the anoxic brine-filled Tyro basin (eastern Mediterranean), Org. Geochem., II( 6), 605-611.

ten Haven, H.L., de Lange, G.J. and McDuff, R.E., 1987. Interstitial water studies of Late Quaternary Eastern Mediterranean sediments with emphasis on early diagenetic reactions and evaporitic salt influences, Mar. Geol., 75(1-4), 119-136.

Thomson, J., Calvert, S.E., Crudeli, D., de Lange, G.J., Slomp, C.P., Erba, E. and Corselli, C., 2004. Florisphaera profunda and the origin and diagenesis of carbonate phases in eastern Mediterranean sapropel units, Paleoceanography, 19, doi: 10.1029/2003PA000976.

Triantaphyllou, M.V., Antonarakou, A., Dimiza, M. and Anagnostou, Ch., 2010. Calcareous nannofossil and planktonic foraminiferal distributional patterns during deposition of sapropels S6, S5 and S1 in the Libyan Sea (Eastern Mediterranean), Geo-Mar Lett., 30, 113.

Troelstra, S.R., 1987. Late Quaternary sedimentation in the Tyro and Kretheus basins, Southeast of Crete, Mar. Geol., 75, 77-91.

Violanti, D., Grecchi, G. and Castradori, D., 1991. Paleoenvironmental interpretation of core BN88$11 \mathrm{GC}$ (eastern Mediterranean, Pleistocene-Holocene) on the ground of foraminifera, Thecosomata and Calcareous nannofossils, il Quaternario, 4(1a), 13-39.

Wallmann, K., Aghib, F.S, Castradori, D., Cita, M.B., Suess, E., Greinert, J. and Rickert, D., 2002. Sedimentation and formation of secondary minerals in the hypersaline Discovery Basin, eastern Mediterranean, Mar. Geol., 186, 9-28. 